\title{
Multiple Representation-Based Learning through Cognitive Dissonance Strategy to Reduce Student's Misconceptions in Volumetric Analysis
}

\author{
Hayuni Retno Widarti ${ }^{1}$, Anna Permanasari ${ }^{2}$, Sri Mulyani ${ }^{2}$, \\ Deni Ainur Rokhim ${ }^{1,3}$, Habiddin ${ }^{1}$ \\ ${ }^{1}$ Faculty of Matchematics and Natural Sciences, Chemsitry Education, Universitas Negeri Malang, \\ Jl. Semarang No. 5, Malang, Indonesia \\ ${ }^{2}$ Faculty of Matchematics and Natural Sciences, Universitas Pendidikan Indonesia, \\ Jl. Dr. Setiabudi No. 229, Bandung, Indonesia \\ ${ }^{3}$ SMAN 3 Sidoarjo, Jl. Dr. Wahidin No 130, Sidoarjo, Indonesia
}

\begin{abstract}
This study aimed to determine the contribution of multiple representation-based learning through cognitive dissonance strategy and to reduce misconceptions encountered by chemistry students. A mixed method research with the embedded experimental design was employed in this study involving 66 sophomore students enrolled in the Basics of Analytical Chemistry class. This study used a threetier test diagnostic test of 43 questions that had been validated by the education teams and chemists. The analysis was done by using a t-test and $\mathrm{N}$-gain. The results showed a significant difference between the experimental and the control classes and a greater increase in $\mathrm{N}$-gain in the experimental class $(68.56 \%)$ compared to the control class $(42.42 \%)$. The most effective reduction of misconceptions occurred in the subject of argentometric titration, from 33.41 to 8.79 $\%$.

This indicates that MRCD cannot completely eliminate misconceptions, especially for concepts related to sub-microscopic and symbolic representations.
\end{abstract}

DOI: 10.18421/TEM103-33

https://doi.org/10.18421/TEM103-33

Corresponding author: Hayuni Retno Widarti,

Universitas Negeri Malang, Indonesia

Email: hayuni.retno.fmipa@um.ac.id

Received: 24 December 2020.

Revised: 09 July 2021.

Accepted: 16 July 2021.

Published: 27 August 2021.

(cc)BY-NC-ND (C) 2021 Hayuni Retno Widarti et al; published by UIKTEN. This work is licensed under the Creative Commons Attribution-NonCommercial-NoDerivs 4.0 License.

The article is published with Open Access at www.temjournal.com
Keywords - cognitive dissonance, misconceptions, multiple representations, volumetric analysis

\section{Introduction}

Basic of Analytical Chemistry (BAC) is an essential course to study as it becomes the basis of chemical analysis and the basis for learning concepts in several other chemistry courses. The materials in BAC course include knowledge of basic statistics, as well as qualitative and quantitative analyses that determine the type and amount of a substance in the sample. The essence of BAC materials related to quantitative analysis was raised by Skoog, West, Holler, \& Crouch [1] who asserted that the measurement of quantitative analysis also plays a pivotal role in various fields such as chemistry, biochemistry, biology, geology, physics, and other sciences, in which analytical chemistry is at the centre of other branches of science. In other words, the BAC course, including quantitative analysis as part of analytical chemistry is a central basic course for students. Quantitative analysis is conventionally designed in two subjects, gravimetric analysis and volumetric analysis.

The volumetric analysis consists of several subjects such as preliminary volumetric analysis, acid-base titration, redox titration, argentometric titration, and titration of complexation reactions. All of these materials are related to basic chemical concepts such as reaction equations, chemical equilibrium, stoichiometry, buffer solutions, acidbase reactions, redox reactions, precipitation reactions, solubility, solubility products, and complex formation reactions. Some researches show that students still encounter difficulties to understand chemical concepts. Sheppard stated students' difficulties in understanding the concept of acid-base 
[2]. Kaya reported that chemical equilibrium is a difficult subject for some students [3]. Orgill \& Sutherland found out that students, in general, often do not understand questions related to buffer solutions [4]. A study suggested that students' difficulties in understanding the concept of chemistry lead to alternative conceptions or misconceptions [2]. According to Luoga, Ndunguru, \& Mkoma, the misconception is an inconsistency of understanding between students' views and experts' views [5].

Students had misconceptions because the characteristics of chemistry are abstract [3]; Herron's statement in [2] and complex, involves algorithmic concepts as well as chemical representations, such as macroscopic, submicroscopic, and symbolic [4]. Habiddin \& Page applied a different approach to identify the difference of university students' ability of a relevant pictorial and algorithmic style questions [7]. Furthermore, Herron's statement in [2], that misconceptions in chemistry exist since the characteristics of chemistry are tiered, a complex chemical concept starts with a simple chemical concept. When students had misconceptions on basic concepts, they had difficulty understanding more complex concepts. This is consistent with Artdej, Ratanaroutai, Coll, \& Thongpanchang [8], and Sesen $\&$ Tarhan [9], that to understand the concept of acidbase, students should first recognize the prerequisite materials, such as chemical equilibrium, chemical reactions, stoichiometry, the nature of matter and solution.

The concept of acid-base is one of the basic concepts used to understand the concept of acid-base titration. Thus, if students have a misconception about the concept, it is likely that they have difficulties in understanding acid-base titration in the BAC course. This can be proven from several research results which showed that students still have misconceptions on basic and complex material in chemistry. Student misconceptions in the concept of acid-base in basic chemistry, errors in acid-base terms and words used daily [2]. Pinarbasi showed that Turkish students had a number of misconceptions about the topic of acid-base [10]. Kaya reported that students usually have several misconceptions about chemical equilibrium in basic chemistry [3]. Widarti, Marfuah, \& Retnosari stated that there were still misconceptions in the course of organic chemistry discussing intermolecular-force [11]. Widarti, Permanasari, \& Mulyani reported that students experienced difficulties and had misconceptions in determining the $\mathrm{pH}$ and species sub-microscopically in a solution before the equivalence point on acid-base titration [12]. According to Cooper, Underwood, \& Hilley [13], if students understand the acid-base concepts well, they will be able to explain the results of various reactions related to acid-base such as buffers, hydrolysis, and acid-base titration.

Given the above-mentioned literature review, it can be concluded that misconceptions are very complicated to eliminate, even through learning. Therefore, innovative learning becomes a practical solution to overcome students' difficulties and misconceptions in the BAC course. A learner must be able to implement appropriate learning strategies to increase concepts understanding and reduce misconceptions. One learning strategy that can be applied to volumetric analysis materials is cognitive dissonance strategy. The use of this strategy is believed to create changes in students. Psychologically, students experience cognitive dissonance in the learning process when accepting concepts that are different from what they already know. According to Festinger, cognitive dissonance encourages a person to be motivated to overcome discrepancies [14]. The person will attempt to overcome the discrepancy in various ways to understand concepts that are different from what has been known. Cognitive dissonance is one of the strategies to create cognitive conflict [15]. Baddock \& Bucat stated that demonstrations in learning with cognitive conflict strategies can be used to encourage students to engage in conceptual change [16]. Rahayu, Chandrasegaran, Treagust, \& Kita, teaching innovations such as cognitive conflict strategy are effective in increasing students' understanding of acid-base concepts [17]. The use of cognitive dissonance strategy needs to be followed up with other strategies that direct students towards ownership of the correct conception. Volumetric analysis material in BAC subjects more often involves chemical reactions, stoichiometry, content calculations, ion species, and the depiction of the titration curve shortly and after the equivalence point, so volumetric analysis requires the use of multiple representations (sub-microscopic, macroscopic, and symbolic) to assist students in understanding this concept as a whole.

The prominence of multiple representations in chemistry learning has been reported in various journal articles. Several studies have shown that learning by using multiple representations can improve students' understanding of chemical concepts both in the classroom and laboratory. Hand $\&$ Choi reported that multiple representations had a positive impact on the ability to construct students' arguments in the laboratory class through the science writing heuristic strategy [18]. Likewise, McDermott \& Hand stated that the use of multiple representations supports the writing-to-learn task as a pedagogical tool in improving chemistry learning in schools [19]. Multiple representations also assist 
students in solving problems with the chemical concept of NMR spectroscopy [20]. The use of multiple representations in learning can also improve students' mental models on the concept of stoichiometry [21]. Therefore, a learning strategy that can help and improve students' understanding of chemical concepts which can simultaneously reduce misconceptions is necessary. Besides, various efforts need to be made to create an innovative learning environment, including using cognitive dissonance strategies to motivate and minimize misconceptions, especially in volumetric analysis material.

Based on the above explanations, it can be stated that multiple representations designed with cognitive dissonance strategy in classroom teachings (face-toface) have the potential to overcome various weaknesses in BAC courses. Learning by using multiple representations can make students encounter a complete concept of volumetric analysis material. Moreover, volumetric analysis material is appropriate when delivered using multiple representations (MR) through cognitive dissonance strategies that can motivate students. This strategy can engage students to increase curiosity related to the given concepts. Therefore, it is necessary to conduct multiple representation-based learning research with cognitive dissonance (MRCD) strategies on volumetric analysis material. In addition, studies on MRCD for strengthening the concept of volumetric analysis materials which include preliminary volumetric analysis, acid-base titration, redox titration, and argentometric titration are rarely reported, so this research is significant. Using MRCD lectures on volumetric analysis can strengthen understanding of concepts which at the same time reduce students' misconceptions in learning the BAC material, especially volumetric analysis.

\section{Method}

\section{Research Design}

Mixed method research with the embedded experimental design was employed in this study [22]. This study was conducted to implement the learning model and to determine the effectiveness of multiple representation-based learning model through cognitive dissonance strategy for reducing misconceptions in volumetric analysis material. Quantitative method was used to examine students' cognitive learning outcomes, while the qualitative method was used to identify the feasibility of multiple representations-based learning models derived from the results of questionnaires and interviews, aside from describing students' misconceptions on volumetric analysis material.

\section{Sample of Research}

The participants of this study were 66 sophomore students enrolled in the BAC course. They were grouped into two classes, experimental and control classes. The experimental class consisted of 35 students with multiple representations-based learning through cognitive dissonance strategy, and 31 students in the control class were treated with expository learning.

\section{Instrument and Procedures}

The research instrument used was a multiplechoice diagnostic test with open reason and level of confidence (three-tier test), questionnaire, and interview guidelines. The instrument containing 43 volumetric analysis questions had been validated and given before learning (pre-test) and after learning implementation (post-test), which included seven preliminary volumetric analysis questions, 14 questions of acid-base titration, nine redox titration questions, and 13 argentometry titration questions. The questionnaire was used to find out the students' responses to classroom teaching.

The implementation of cognitive dissonance in this study follows the learning syntax: (1) Inviting students' prior knowledge, (2) Creating cognitive dissonance, (3) Implementing the novel knowledge and feedbacks, (4) Reflection, (5) Closure.

The lecturer provided an additional explanation regarding the topic. Before closing the class, the lecturer informed the students regarding the topic for the next meeting.

\section{Data Analysis}

Misconception identification was done by combining two developed instruments, multiplechoice tests with open reasoning and the Certainty of Response Index (CRI) scale technique modified by Hasan, Bagayoko, \& Kelley [23], Hakim, Liliasari, \& Kadarohman [24], Potgieter, Malatje, Gaigher, \& Venter [25] and Habiddin \& Page [26]. From the results of these modifications, there are eight types of abilities according to various answers, reasons, and students' beliefs. The analysis of each type of students' understanding is shown in Table 1. 
Table 1. Modified CRI classifications for each answer

\begin{tabular}{ccclc}
\hline Answer & Reason & CRI Value & \multicolumn{1}{c}{ Description } & Label \\
\hline Correct & Correct & $>2.5$ & Understand the concept well & P1 \\
Correct & Correct & $<2.5$ & Understand the concept with a doubtful answer & P2 \\
Correct & Incorrect & $>2.5$ & Misconception & M1 \\
Correct & Incorrect & $<2.5$ & Fail to understand the concept & T1 \\
Incorrect & Correct & $>2.5$ & Misconception & M2 \\
Incorrect & Correct & $<2.5$ & Fail to understand the concept & T2 \\
Incorrect & Incorrect & $>2.5$ & Misconception & M3 \\
Incorrect & Incorrect & $<2.5$ & Fail to understand the concept & T3 \\
\hline
\end{tabular}

The main stages in this study, according to Linenberger \& Bretz [27], include four phases: (1) bringing up previous knowledge by reminding the students about previous related materials, (2) creating cognitive dissonance and building knowledge with multiple appropriate representations, (3) applying new knowledge with feedback which was carried out within-group discussions by using student worksheets, and (4) reflections to obtain conclusions.

Qualitative data obtained during the implementation of the MRCD were analysed using qualitative descriptive analysis by calculating the percentage of answers given by students in each statement. Meanwhile, the quantitative data analysis used statistical average test difference (t-test). Statistical tests were in the form of homogeneity, normality, and average difference test scores between the experimental group and the control group. Quantitative data analysis also calculated the percentage of normalized gain of each student with the formula of N-gain (Hake, in [28]:

$$
\% g=\frac{\left(S_{\text {post }}-S_{\text {pre }}\right)}{\left(S_{\text {max }}-S_{\text {pre }}\right)} \times 100
$$

with $\% \mathrm{~g}=$ normalized gain percentage, $\mathrm{S}_{\text {post }}=$ final test score, $\mathrm{S}_{\text {pre }}=$ initial test score, and $\mathrm{S}_{\max }=$ maximum score. $\mathrm{N}$-gain values are classified into categories, high $(\% \mathrm{~g}>70)$, moderate $(30 \leq \% \mathrm{~g} \leq$ $70)$, and low $(\% \mathrm{~g}<30)$.

\section{Results and Discussion}

Based on the results of the instrument validation obtained, $90 \%$ of the instruments were suitable for use with several revisions. From the 43 questions, there were four invalid questions which were then corrected. The reliability test results obtained a value of $0.946(>0.60)$ which means the questions made are reliable. The results of students' mastery of concepts at pre-test and post-test are quantitative stages during the implementation of the MRCD. Learning outcomes on volumetric analysis material in the experimental class and the control class in the form of an average score of pre-test, post-test, and $\mathrm{N}$-gain are presented in Table 2.

Table 2. shows that the average score of the experimental group in the pre-test is 37.63 and the score of the control class is 43.00. Table 2. also indicates the average score of the experimental class post-test at 79.86 and the control class at 67.35 . Posttest data from both groups portray that there is an increase in mastery of concepts, especially in volumetric analysis material. The increase in the average score of the percentage of $\mathrm{N}$-gain in the experimental class is $68.56 \%$, and the control class is $42.42 \%$. In this study, a statistical test analysis ( $\mathrm{t}-$ test) was performed. The results of the analysis in the pre-test, post-test, and $\mathrm{N}$-gain of the experimental group and control group can be seen in Table 3 .

Table 2. Average scores of student learning outcomes in Volumetric analysis

\begin{tabular}{ccccccc}
\hline \multirow{2}{*}{ Data } & \multicolumn{3}{c}{ Experimental Class } & \multicolumn{3}{c}{ Control Class } \\
\cline { 2 - 7 } & Pre-test & Post-test & \% N-gain & Pre-test & Post-test & \% N-gain \\
\hline $\mathrm{N}$ & 35 & 35 & & 31 & 31 & \\
$\bar{X}$ & 37.63 & 79.86 & 68.56 & 43.00 & 67.35 & 42.42 \\
$\mathrm{Sd}$ & 9.89 & 11.07 & 1.54 & 14.00 & 13.72 & 1.98 \\
\hline
\end{tabular}

Table 3. Statistical calculation of pre-test, post-test, and N-gain scores

\begin{tabular}{|c|c|c|c|c|c|c|c|c|}
\hline \multirow{3}{*}{ No } & \multirow{3}{*}{ Data } & \multicolumn{4}{|c|}{ Normality Test $(\alpha=0.05)$} & \multirow{3}{*}{ Hom (P) } & \multirow{3}{*}{$\begin{array}{c}\text { t-test } \\
(\alpha=0,05)\end{array}$} & \multirow{3}{*}{ Note } \\
\hline & & \multicolumn{2}{|c|}{$\mathbf{P}$} & \multicolumn{2}{|c|}{ Criteria } & & & \\
\hline & & Experiment & Control & Experiment & Control & & & \\
\hline 1 & Pre-test & 0.091 & 0.200 & Normal & Normal & 0.079 (hom) & 0.074 & Insignificant \\
\hline 2 & Post-test & 0.045 & 0.139 & Unnormal & Normal & 0.302 (hom) & 0.000 & Significant \\
\hline 3 & $\mathrm{~N}$-gain & 0.200 & 0.200 & Unnormal & Normal & 0.075 (hom) & 0.000 & Significant \\
\hline
\end{tabular}


Based on the results of the analysis of different tests (t-test) of the pre-test score from the two classes, it can be concluded that, in general, the students' ability before the learning process was not significantly different. This finding could be because the two classes had not received treatment related to the material being tested. The results of the analysis of the difference in the average post-test and N-gain scores indicated that there were significant differences in the ability between the experimental and control classes. This result showed an increase in mastery of concepts in the experimental class in the medium category and the control class in the low category [29]. The results indicated that the ability of the experimental class was higher than the control class after the learning process. This outcome suggests that MRCD-based learning is better in increasing mastery of the BAC concepts compared to conventional learning. In other words, MRCD-based learning can reduce students' misconceptions.

\section{Students' Misconceptions on the BAC Concept}

Table 4. presents the analysis of the percentage of categories of students who experienced misconceptions based on the CRI method (Table 1.) on the volumetric analysis material for both groups.
Table 4. Percentage of misconceptions of the experimental and control classes

\begin{tabular}{ccc}
\hline Class & Pre-test (\%) & Post-test (\%) \\
\hline Experiment & 34.15 & 15.69 \\
Control & 19.20 & 24.79 \\
\hline
\end{tabular}

As Table 4. indicates, the misconception of the control class is smaller than that of the experimental class. The reason for this is because students in the control class tended to be dominant in answering questions with a low level of confidence. The opposite occurred in the experimental class, where misconception in pre-test was higher. The pre-test in the experimental class corresponded to the CRI scale with a high level of confidence.

The percentage of misconception categories at each subject on volumetric analysis material for both groups is presented in Table 5. The highest percentage of misconceptions of experimental class pre-tests occurred at the preliminary subject of volumetric analysis, and a similar condition happened in the control class. In the post-test, the percentage of misconceptions of the experimental class occurred in the preliminary subject of volumetric analysis, which was similar to the percentage of misconceptions on redox titration. The same thing happened in the control class, where the highest percentage of misconceptions occurred in the preliminary subject of volumetric analysis.

Table 5. Recapitulation of percentage of misconceptions of Volumetric analysis in the experimental and the control classes

\begin{tabular}{lcccc}
\hline \multirow{2}{*}{\multicolumn{1}{c}{ Topic of Discussion }} & \multicolumn{3}{c}{ Percentage of Misconception } \\
\cline { 2 - 4 } & \multicolumn{2}{c}{ Experimental Class } & \multicolumn{2}{c}{ Control Class } \\
\cline { 2 - 4 } & Pre-test & Post-test & Pre-test & Post-test \\
\hline Introduction to Volumetric Analysis & 53.47 & 21.63 & 45.62 & 40.09 \\
Acid-Base Titration & 28.98 & 15.51 & 17.74 & 18.43 \\
Redox Titration & 28.25 & 21.59 & 13.98 & 32.26 \\
Argentometric Titration & 33.41 & 8.79 & 10.17 & 14.64 \\
\hline
\end{tabular}

Table 5. shows that after BAC-MRCD learning, there is an alteration in the number of students' misconceptions. The percentage of students experiencing misconceptions decreased. However, the misconception could not be lost either before the implementation or after the implementation of the BAC-MRCD program. This result is in line with what was stated by Pinarbasi, Sozbilir, \& Canpolat [30], that misconceptions are very difficult to change. This case is consistent with the characteristics of misconceptions such as being durable and firmly embedded in one's mind [5].

Based on the answers, there are three types of misconceptions, namely M1, M2, and M3. Analysis based on the types of students' misconceptions for each subject can be seen in Table 6. The highest percentage of misconceptions in the experimental class and the control class pre-tests both occurred in the type of ability label M3, namely in the preliminary subject of volumetric analysis.

Table 6. Percentage of misconceptions in each subject based on the type of students' capability according to CRI

\begin{tabular}{|c|c|c|c|c|c|c|c|c|c|c|c|c|}
\hline \multirow{3}{*}{ Concept } & \multicolumn{6}{|c|}{ Experimental Class } & \multicolumn{6}{|c|}{ Control Class } \\
\hline & \multicolumn{2}{|c|}{ M1 } & \multicolumn{2}{|c|}{ M2 } & \multicolumn{2}{|c|}{ M3 } & \multicolumn{2}{|c|}{ M1 } & \multicolumn{2}{|c|}{ M2 } & \multicolumn{2}{|c|}{ M3 } \\
\hline & Pre & Post & Pre & Post & Pre & Post & Pre & Post & Pre & Post & Pre & Post \\
\hline PAV & 0.00 & 1.22 & 0.00 & 0.00 & 53.47 & 20.41 & 2.77 & 2.30 & 0.00 & 0.00 & 42.86 & 37.80 \\
\hline TAB & 9.39 & 1.63 & 0.00 & 0.00 & 19.59 & 13.88 & 6.45 & 2.53 & 0.00 & 0.46 & 11.29 & 15.44 \\
\hline TR & 381 & 1.91 & 0.00 & 0.00 & 24.44 & 19.68 & 2.87 & 1.43 & 0.00 & 0.00 & 11.11 & 30.83 \\
\hline TA & 1.54 & 1.10 & 0.00 & 0.00 & 31.87 & 7.69 & 6.70 & 1.00 & 0.00 & 0.00 & 3.47 & 13.65 \\
\hline
\end{tabular}

Notes: $\mathrm{PAV}=$ Introduction to volumetric analysis, $\mathrm{TR}=$ Redox titration, $\mathrm{TAB}=$ Acid base titration, $\mathrm{TA}=$ Argentometric titration 
The results presented in Table 6 . indicate that students who often experience misconceptions had high confidence with incorrect answers and reasons. The highest percentage of misconceptions in the experimental class and the control class both occurred in the identical label, M3, in the preliminary volumetric analysis material.

\section{Introduction to Volumetric Analysis}

In the preliminary subject of volumetric analysis, both in the pre-test and post-test, the experimental class and the control class showed the highest percentage compared to other subjects. The highest percentage of misconceptions is related to answers to questions number 1, 4, 5, and 7 (glassware selection, Erlenmeyer flask flushing, flushing technique during titration, and titration calculation) with M3 misconception type. Prior to the implementation of BAC-MRCD learning, students experienced many M3 pattern misconceptions. This happened because the students just answered without giving a right or wrong reason. After the implementation of the BACMRCD, the misconception decreased and the pattern of misconception changed to M3, although both cases happened to very few students (1-2 students).
Students' misconceptions on problem number 4, that is the students assumed that before the titration was performed the Erlenmeyer that would be used must be washed with $\mathrm{HCl}$, dried with tissue paper and some were directly used. The correct concept is the tool (Erlenmeyer flask), where the concentration of a sample or titrate will be sought, should be dry and clean. The next misconception occurred in problem number 5. Students assumed that when performing a titration, it was not permissible to rinse the Erlenmeyer flask walls with distilled water so that the concentration or amount of the substance does not change. The next misconception occurred in problem number 7. Students assumed that the number of mmol of oxalic acid was the same as mmol of $\mathrm{NaOH}$ at the endpoint of the titration, without considering the chemical equation that occurred. Besides that, actually, students must also consider the equality aspects of $\mathrm{H}^{+}$and $\mathrm{OH}^{-}$ions in chemical equations. The misconception in problem number 1 was to take the volume of the sample solution to be titrated by using a measuring pipette, not the volume pipette or the goiter pipette.

The worst misconception in the preliminary volumetric analysis was related to the use of tools and stoichiometry, as shown in Table 7.

Table 7. Students' misconceptions in the preliminary subject of volumetric analysis

\begin{tabular}{cl}
\hline Number & \multicolumn{1}{c}{ Misconception } \\
\hline 1 & $\begin{array}{l}\text { Taking the volume of the sample solution to be titrated by using: pipette, measurement cup } \\
\text { Prior to titration, Erlenmeyer must be washed with } \mathrm{HCl} \text { and dried with tissue paper }\end{array}$ \\
5 & $\begin{array}{l}\text { Erlenmeyer is used for titration } \\
\text { When titrating, it is not permissible to rinse the walls of the Erlenmeyer flask with distilled water in order } \\
\text { the concentration or amount of the substance does not change } \\
\text { The number of mmol of oxalic acid is the same as the mmol of NaOH at the endpoint of the titration, } \\
\text { regardless of the chemical equation that occurs }\end{array}$ \\
\hline
\end{tabular}

\section{Acid-Base Titration}

The subject of acid-base titration consists of 14 questions asking about the concept of acid-base titration. Prior to conducting the lecture using the BAC-MRCD, misconceptions that appeared in the aspect of determining the $\mathrm{pH}$ of the titration of the acetic acid solution with sodium hydroxide solution before adding sodium hydroxide solution and before the equivalence point described the species involved in the process of acid-base titration and the selection of indicators. After the BAC-MRCD lecture, there was a decrease in the percentage of students' misconceptions.

In the subject of acid-base titration, the percentage of misconceptions in the pre-test and post-test of the experimental class indicated a decrease from 28.98 to $15.51 \%$. However, in the control class, it increased from 17.74 to $18.43 \%$. Prior to implementing the BAC-MRCD lectures, the highest misconceptions happened in questions number 10 , $11,12,18$, and 19. The misconceptions experienced by students before implementing the BAC-MRCD lecture program are as follows: 1) students assumed at point $\mathrm{K}$ before adding $\mathrm{NaOH}$ solution $\mathrm{pH}=0$ in acetic acid solution with sodium hydroxide (number 10), 2); students answered that the equivalent points of the ion species present in the solution were $\mathrm{H}_{3} \mathrm{O}^{+}$, $\mathrm{CH}_{3} \mathrm{COO}$, and $\mathrm{OH}^{-}$; there were also students who answered that $\mathrm{Na}^{+}$had reacted completely and was not in solution (number 11). 3). The students were wrong in calculating $\mathrm{pH}$ using weak acid $\mathrm{pH}$ (number 12). 4). The students answered that before the equivalence point, there was an $\mathrm{H}_{3} \mathrm{O}^{+}$(number 18). 5). The students were wrong and their reason did not answer the question asked in determining the indicator (number 19). All misconceptions prior to the implementation occurred with M3 and M1 patterns. After the implementation of the BACMRCD, the misconceptions decreased. The 
dominant misconception occurred in the aspects describing the species involved in the acid-base titration process. Based on the studies, the misconceptions occurred because the students were not careful enough to understand the form of representation of ions given to the questions and lack of understanding of the titration process. The students' misconceptions on the subject of acid-base titration can be seen in Table 8 .

Table 8. Students' misconceptions on the subject of acid-base titration

\begin{tabular}{cl}
\hline Number & \multicolumn{1}{c}{ Misconceptions } \\
\hline 10 & Before adding $\mathrm{NaOH}$ to Erlenmeyer containing acetic acid, $\mathrm{pH}=0$ \\
11 & $\begin{array}{l}\text { Before the equivalent point of the ion species present in the solution are } \mathrm{H}_{3} \mathrm{O}^{+}, \mathrm{CH}_{3} \mathrm{COO}, \mathrm{and}^{-} \mathrm{OH}^{-} . \mathrm{Na}^{+} \\
\text {has reacted and is not in solution }\end{array}$ \\
12 & Calculate the pH before the equivalence point using the pH of a weak acid \\
19 & Before the equivalent point, there is an $\mathrm{H}_{3} \mathrm{O}^{+}$ion when the equivalent point is an excess of $\mathrm{HCl}$ \\
\hline
\end{tabular}

\section{Redox Titration}

The subject of redox titration consists of nine questions asking about stoichiometry. On the subject of redox titration, the percentage of misconceptions in the pre-test and post-test of the experimental class showed a decrease, $28.25 \%$ in the pre-test and $21.59 \%$ in the post-test. The opposite happened in the control class where misconceptions increased. The pattern of misconceptions that emerged remained the same in the M3 and M1 patterns and almost spread to all problems related to redox titration. Prior to the BAC-MRCD lecture program, misconceptions often arose in the stoichiometric aspects, dominant ion species in determining potential after the equivalence point, and the concept of redox titration. After the implementation, the dominant misconception occurred in the same aspects and the diversity was not much different. The students' misconceptions on the subject of redox titration can be seen in Table 9 .

Table 9. Students' misconceptions in the subject of redox titration

\begin{tabular}{|c|c|}
\hline Number & Misconception \\
\hline 22 & $\begin{array}{l}\text { In the stoichiometry aspect, students generally } \\
\text { used the dilution formula and did not write down } \\
\text { the equation of the reaction that occurred }\end{array}$ \\
\hline 23 & $\begin{array}{l}\text { Before the equivalent points, the dominant ions } \\
\text { in determining potential were } \mathrm{Fe}^{2+}, \mathrm{Fe}^{3+}, \& \mathrm{Ce}^{4+}\end{array}$ \\
\hline 25 & $\begin{array}{l}\text { After the equivalent points, the dominant ion } \\
\text { species in determining potential were } \mathrm{Ce}^{3+}, \mathrm{Ce}^{4+} \text {, } \\
\text { and } \mathrm{Fe}^{3+}\end{array}$ \\
\hline 29 & $\begin{array}{l}\text { In the chromatometry titration, an oxidation } \\
\text { reaction occurred from } \mathrm{Cr}_{2} \mathrm{O}_{7}^{2-} \text { to } \mathrm{Cr}^{3+} \text { and the } \\
\text { iodide ion acted as a reducing agent in the } \\
\text { iodometric titration }\end{array}$ \\
\hline
\end{tabular}

\section{Argentometric Titration}

The subject matter of argentometric titration consists of 13 questions asking about stoichiometry and the concept of argentometric titration. On the subject of argentometric titration, the percentage of misconceptions in the pre-test and post-test of the experimental class showed a decrease, $33.41 \%$ (pretest) and $8.79 \%$ (post-test). The opposite happened in the control class where misconceptions increased. Before the BAC-MRCD lecture program was implemented, the dominant misconception was spread to almost all concepts. After the implementation of the BAC-MRCD lecture program, there was a decrease in the percentage of students' misconceptions on almost all concepts in the argentometry titration. The dominant pattern of the misconception was M3. The students' misconceptions on the subject of argentometric titration can be seen in Table 10 .

Table 10. Students' misconceptions on the subject of argentometry titration

\begin{tabular}{|c|c|}
\hline Number & Misconception \\
\hline $31 \& 42$ & $\begin{array}{l}\text { In the stoichiometry aspect, students } \\
\text { mistakenly wrote the reaction equation and } \\
\text { interpreted the reaction }\end{array}$ \\
\hline $33-37$ & $\begin{array}{l}\text { Students were wrong in determining the } \\
\text { ions contained in the solution during the } \\
\text { titration process and in determining } \mathrm{pCl}\end{array}$ \\
\hline 41 & $\begin{array}{l}\text { Students mistakenly calculated } \mathrm{pCl} \text { and } \\
\text { misinterpreted into the curve }\end{array}$ \\
\hline
\end{tabular}

From the tendency of all misconceptions that arose in the BAC subjects, especially in volumetric analysis material. This is because a misconception in quantitative chemical analysis is fatal. After all, it can affect the results of subsequent analyses.

From the results of the research and analysis of the findings, it can be concluded that there was a decrease in misconceptions in all subjects, which resulted in an increase in students' concept mastery. The decrease in misconceptions and misconceptions that still appeared in all subjects can be seen in Table 11. 
Table 11. Dominant misconceptions in each subject after the MRCD

\begin{tabular}{|c|c|c|c|}
\hline No & Topic of Discussion & $\begin{array}{l}\% \text { misconceptions } \\
\text { reduction }\end{array}$ & Dominant misconception \\
\hline 1 & $\begin{array}{l}\text { Introduction to Volumetric } \\
\text { Analysis }\end{array}$ & 53.47 to 21.63 & The utilization of tools and stoichiometry \\
\hline 2 & Acid-Base Titration & 28.98 to 15.51 & $\begin{array}{l}\text { Sub-microscopic description of ions presented in the } \\
\text { acid-base titration process }\end{array}$ \\
\hline 3 & Redox Titration & 28.25 to 21.59 & $\begin{array}{l}\text { Stoichiometry, ions before the equivalent points, and the } \\
\text { concept of redox titration }\end{array}$ \\
\hline 4 & Argentometry Titration & 33.41 to 8.79 & Interpretation of the titration curve \\
\hline
\end{tabular}

The BAC-MRCD lecture program is a new innovation teaching program that combines multiple representations with cognitive dissonance strategies. In general, the BAC-MRCD lecture program could reduce the emergence of misconceptions in the four topics. The misconceptions tended to decrease from lectures of the first subject to the fourth subject so that it resulted in an increase in students' understanding. This result is consistent with the results of previous studies. Research conducted by Rahayu et al. reported that teaching innovations such as cognitive conflict strategies were effective in increasing understanding of acid-base concepts [17]. Cognitive dissonance is one of the strategies to create cognitive conflict [15]. Furthermore, multiple representations are very important in chemistry learning. Hand \& Choi reported that multiple representations had a positive impact on the ability to construct students' arguments in the laboratory class through the science writing heuristic strategy [18]. Multiple representations also assist students in solving problems with the chemistry concept of NMR spectroscopy [20].

However, after the BAC-MRCD lectures by using various representations in lectures, misconceptions still appeared on volumetric analysis material. Misconceptions before using the BAC-MRCD lecture program can be found in the control class. The control class was used because it represented previous BAC learning. Basically, the pattern of misconceptions that occurred before and after the implementation of BAC-MRCD was similar, only a different percentage of some students experiencing misconceptions.

From the observations, it can be seen that the students' misconceptions were binding and difficult to remove. There were still common misconceptions in the volumetric analysis. This is in accordance with the characteristics of misconception, which are durable and firmly embedded in one's mind [5]. Misconceptions are very resistant to change [10] and replace with appropriate ones [31]. However, by using the developed program, there was a decrease in misconceptions in all subjects.

\section{Implementation of BAC-MRCD Lecture Program}

In the final stage of lecture activities, students were given a questionnaire that contains statements to identify students' responses to lectures that had been carried out. The percentage of average questionnaire results of students' responses to the BAC-MRCD recovery is shown in Table 12 .

Table 12. Percentage of students' responses to the implementation of MRCD lectures

\begin{tabular}{clcc}
\hline \multirow{2}{*}{ No } & \multirow{2}{*}{ Measured aspects } & \multicolumn{2}{c}{ Responses (\%) } \\
\cline { 3 - 4 } & & Positive & Negative \\
\hline 1 & Multiple representations & 90.39 & 9.51 \\
2 & Cognitive dissonance & 69.35 & 30.65 \\
3 & Content & 95.80 & 4.20 \\
4 & Task & 88.00 & 12.00 \\
5 & Motivation & 89.70 & 10.30 \\
\hline
\end{tabular}

From the results of the questionnaire (Table 12.), it can be seen that students gave positive responses to the MRCD-based lectures. The students' positive responses were related to the use of multiple highest representations $(100 \%)$ to the statement that the use of MR can reduce misconceptions when calculating $\mathrm{pH}$ at the titration before, during, and after the endpoint of the titration. Regarding cognitive dissonance in lectures, the highest positive student responses to statements about the questions given to lectures indicate that the students want to find out more about volumetry. Regarding content, all respondents had positive responses to the content of volumetric analysis material. Students thought that the task of making a titration curve helped to understand the titration process. Likewise, assignments represent problems in the Student Worksheet to help students understand and solve problems. The lectures that took place could also motivate and spark the enthusiasm of the students to learn better. Students gave a high positive response to statements related to the new BAC concept which students tried to understand.

The results of students' responses in Table 12 . show that the application of the MRCD-based lecture programs could motivate the student in learning. These results corresponded to a reduction in misconceptions that could increase mastery of 
concepts, especially in the volumetric analysis material. In general, students' responses after BACMRCD learning were mostly positive. Positive responses were seen in the use of representation, assignments, and exercises given questions that were very helpful to students' understanding. The lectures that were carried out also could lead to students' motivation to understand the concept well.

From Table 5., it can be seen that misconceptions still appeared in all subjects. This finding is consistent with the opinion of experts that misconceptions are difficult to disappear among students at all levels of education, both primary and higher education. This also happens in the BAC lectures in tertiary institutions. Therefore, some efforts should be made to minimize misconceptions. The BAC-MRCD lecture program has successfully minimized students' misconceptions. The BACMRCD lecture combines lecture activities using cognitive dissonance strategies and various representations in the form of images, curves, and videos with related questions. The questioning is intended to cause cognitive dissonance. Cognitive dissonance will motivate students to try to understand and find answers to questions so that there is a change in the students' concept towards a complete understanding. The BAC-MRCD lecture program also provides an opportunity for students to interact with other students through group discussions in finding information about practice questions and completing Worksheet assignments.

The results showed that the MRCD-based lecture program on volumetric analysis material applied to the experimental class could improve concept mastery compared to the control class. This suggests that lectures on volumetric analysis materials based on multiple representations through cognitive dissonance (MRCD) strategies provide opportunities for students to discover concepts, connect new concepts with existing knowledge, and solve problems related to volumetric analysis using various cognitive dissonance representations and strategies. This result aligns with Linenberger \& Bretz research indicating that adding a second representation on the same topic raises students' cognitive dissonance, which increases students' motivation to understand concepts well [27]. However, the results of the implementation of learning were not yet able to reduce misconceptions totally. These results are consistent with the opinion of Santos \& Arroio, that students who acquire knowledge without a clear understanding or experience misconceptions, may become confused because they have to deal with multiple representations simultaneously [32].

The use of multiple representations in research is supported by cognitive dissonance strategies. It is expected that cognitive dissonance (cognitive conflict) that arises encourages students to be more challenged to find out the true concept. Domin \& Bodner also reported that the use of multiple representations helped students solve problems in chemistry concepts [20].

The results showed that the application of MRCDbased lecture programs could increase mastery of acid-base material. This improvement could be seen after students were given treatment through the MRCD lectures. Then, they were given a post-test to find out the conception changes that occurred in students' cognitive. This result is supported by the opinion of Rahayu et al. that misconceptions can be overcome by using innovative lecture models [17]. One of the models can be applied using cognitive conflict strategies. The same opinion was also proposed by Hand \& Choi, that multiple representations had a positive impact on students' ability to construct arguments [18]. Likewise, McDermott \& Hand stated that the use of multiple representations supported the writing-to-learn task as a pedagogical tool for improving chemistry learning in schools [19]. Domin \& Bodner also reported that the use of multiple representations helped students solve problems in chemistry concepts [20]. According to Guzel \& Adadan, multiple representations in teaching were useful for developing the understanding of prospective chemistry teachers and maintaining the understanding within a certain period [6]. Research on cognitive dissonance in chemistry through multiple representations has been done by Linenberger \& Bretz [27], indicating that the combination of representations encouraged students to make connections between representations.

Based on the research results and data analysis, the BAC-MRCD lecture program can give students insights into the use of multiple chemical representations in macroscopic, sub-microscopic and symbolic, as well as motivate students to increase their understanding by being more diligent in learning and seeking appropriate literature sources through various means. Besides that, BAC-MRCD lecture program can train students to accept and adapt mastered concepts with new concepts and encourage students to practice together when conducting group discussions.

Some limitations were identified in the implementation of the BAC-MRCD lecture. First, the prepared lecture programs could not optimally overcome students' misconceptions, and the suboptimal representation was not yet optimal for all subjects. The implementation was also still constrained by the media used, which sometimes had problems when they were used, and the recording of the emergence of cognitive dissonance was not yet optimal. 


\section{Conclusion}

Based on this study, it can be concluded that the BAC-MRCD lecture program on volumetric analysis material could reduce students' misconceptions in four subjects. In the preliminary subject of volumetric analysis (use of tools and stoichiometry), misconceptions decreased from 53.47 to $21.63 \%$; for acid-base titration (sub-microscopic picture of ions present during the titration process) the misconceptions decreased from 28.98 to $15.51 \% \%$; for redox titration (determination of levels, ion species before the equivalent point, and the concept of redox titration), the misconceptions decreased from 28.2 to $21.6 \%$, and for argentometric titration (interpreting the titration curve), it decreased from 33.4 to $8.8 \%$. The dominant type of misconception was M3, then M1 was very small, and M2 was absent. M2 misconception is indeed impossible unless there is an error in writing the answer choices.

The results of this study further indicate that the BAC-MRCD lecture program could improve the mastery of volumetric analysis material. The highest increase occurred in the subject matter of argentometric titration, followed by redox titration, and preliminary volumetric analysis. The lowest one was acid-base titration. The BAC-MRCD lecture program received positive responses from students. The use of multiple representations and cognitive dissonance strategies, according to the students, could help them in constructing abstract knowledge, especially related to the speciation of ions involved in reactions, and reaction equations. The students stated that content in the volumetric analysis is essential because it is related to other subjects. Assignments are given to help students understand and solve problems so that they fully engage in learning.

Furthermore, the use of the BAC-MRCD strategy encompasses several advantages such as (1) increasing students' understandings in the use of multiple representations, (2) motivating students, (3) training them to adapt with new concepts, and (4) encouraging the students to work together albeit the fact that this strategy cannot successfully alleviate misconceptions.

\section{References}

[1]. Skoog, D. A., West, D. M., Holler, F. J., \& Crouch, S. R. (2013). Fundamentals of analytical chemistry. Cengage learning.

[2]. Sheppard, K. (2006). High school students' understanding of titrations and related acid-base phenomena. Chemistry Education Research and Practice, 7(1), 32-45. doi: 10.1039/B5RP90014J.
[3]. Kaya, E. (2013). Argumentation Practices in Classroom: Pre-service teachers' conceptual understanding of chemical equilibrium. International Journal of Science Education, 35(7), 1139-1158. doi: 10.1080/09500693.2013.770935.

[4]. Orgill, M., \& Sutherland, A. (2008). Undergraduate chemistry students' perceptions of and misconceptions about buffers and buffer problems. Chemistry education research and practice, 9(2), 131-143.

[5]. Luoga, N. E., Ndunguru, P. A., \& Mkoma, S. L. (2013). High school students' misconceptions about colligative properties in chemistry. TaJONAS: Tanzania Journal of Natural and Applied Sciences, 4(1), 575-581.

[6]. Yakmaci-Guzel, B., \& Adadan, E. (2013). Use of Multiple Representations in Developing Preservice Chemistry Teachers' Understanding of the Structure of Matter. International Journal of Environmental and Science Education, 8(1), 109-130.

[7]. Habiddin, H., \& Page, E. M. (2021). Examining students' ability to solve algorithmic and pictorial style questions in chemical kinetics. International Journal of Science and Mathematics Education, 19(1), 65-85.

[8]. Artdej, R., Ratanaroutai, T., Coll, R. K., \& Thongpanchang, T. (2010). Thai Grade 11 students' alternative conceptions for acid-base chemistry. Research in Science \& Technological Education, 28(2), 167-183. doi: 10.1080/02635141003748382

[9]. Sesen, B. A., \& Tarhan, L. (2011). Active-learning versus teacher-centered instruction for learning acids and bases. Research in Science \& Technological Education, 29(2), 205-226.

[10]. Pinarbasi, T. (2007). Turkish Undergraduate Students'misconceptions on Acids and Bases. Journal of Baltic Science Education, 6(1).

[11]. Widarti, H. R., Marfuaf, S., \& Retnosari, R. (2019). Identifying Students'misconception About Intermolecular Forces Topic in Organic Chemistry I Course. Unnes Science Education Journal, 8(1).

[12]. Widarti, H., Permanasari, A., \& Mulyani, S. (2017). Undergraduate Students'misconception on Acid-Base and Argentometric Titrations: A Challenge To Implement Multiple Representation Learning Model With Cognitive Dissonance Strategy. International Journal of education, 9(2), 105-112.

[13]. Cooper, M. M., Underwood, S. M., \& Hilley, C. Z. (2012). Development and validation of the implicit information from Lewis structures instrument (IILSI): do students connect structures with properties?. Chemistry Education Research and Practice, 13(3), 195-200. doi: 10.1039/C2RP00010E.

[14]. Festinger, L. (1957). A theory of cognitive dissonance (Vol. 2). Stanford university press.

[15]. Lee, G., Kwon, J., Park, S. S., Kim, J. W., Kwon, H. G., \& Park, H. K. (2003). Development of an instrument for measuring cognitive conflict in secondary-level science classes. Journal of Research in Science Teaching: The Official Journal of the National Association for Research in Science Teaching, 40(6), 585-603. doi: 10.1002/tea.10099 
[16]. Baddock, M., \& Bucat, R. (2008). Effectiveness of a classroom chemistry demonstration using the cognitive conflict strategy. International Journal of Science Education, 30(8), 1115-1128. doi: 10.1080/09500690701528824

[17]. Rahayu, S., Chandrasegaran, A. L., Treagust, D. F., Kita, M., \& Ibnu, S. (2011). Understanding acid-base concepts: Evaluating the efficacy of a senior high school student-centred instructional program in Indonesia. International Journal of Science and Mathematics Education, 9(6), 1439-1458.

[18]. Hand, B., \& Choi, A. (2010). Examining the impact of student use of multiple modal representations in constructing arguments in organic chemistry laboratory classes. Research in Science Education, 40(1), 29-44. doi: $10.1007 /$ s11165-009-9155-8

[19]. McDermott, M. A., \& Hand, B. (2013). The impact of embedding multiple modes of representation within writing tasks on high school students' chemistry understanding. Instructional Science, 41(1), 217-246. doi: $10.1007 / \mathrm{s} 11251-012-9225-6$

[20]. Domin, D., \& Bodner, G. (2012). Using students' representations constructed during problem solving to infer conceptual understanding. Journal of Chemical Education, 89(7), 837-843. doi: 10.1021/ed1006037

[21]. Sunyono, S., Yuanita, L., \& Ibrahim, M. (2015). Mental Models of Students on Stoichiometry Concept in Learning by Method Based on Multiple Representation. The Online Journal of New Horizons in Education (TOJNED), 5(2), 30-45.

[22]. Creswell, J. W., \& Clark, V. L. P. (2017). Designing and conducting mixed methods research. Sage publications.

[23]. Hasan, S., Bagayoko, D., \& Kelley, E. L. (1999). Misconceptions and the certainty of response index (CRI). Physics education, 34(5), 294-299.

[24]. Hakim, A., \& andAsep Kadarohman, L. (2012). Student Concept Understanding of Natural Products Chemistry in Primary and Secondary Metabolites Using the Data Collecting Technique of Modified CRI. International Online Journal of Educational Sciences, 4(3), 544-553.
[25]. Potgieter, M., Malatje, E., Gaigher, E., \& Venter, E. (2010). Confidence versus performance as an indicator of the presence of alternative conceptions and inadequate problem-solving skills in mechanics. International journal of science education, 32(11), 1407-1429. doi: 10.1080/09500690903100265

[26]. Habiddin, H., \& Page, E. M. (2019). Development and validation of a four-tier diagnostic instrument for chemical kinetics (FTDICK). Indonesian Journal of Chemistry, 19(3), 720-736. doi: 10.22146/ijc.39218

[27]. Linenberger, K. J., \& Bretz, S. L. (2012). Generating cognitive dissonance in student interviews through multiple representations. Chemistry education research and practice, 13(3), 172-178.

[28]. Jatmiko, B., Widodo, W., Martini, B., Wicaksono, I., \& Pandiangan, P. (2016). Effectiveness of the INQFbased learning on a general physics for improving student's learning outcomes. Journal of Baltic Science Education, 15(4), 441.

[29]. Abbott, M. L. (2014). Understanding educational statistics using Microsoft Excel and SPSS. John Wiley \& Sons.

[30]. Pinarbasi, T., Sozbilir, M., \& Canpolat, N. (2009). Prospective chemistry teachers' misconceptions about colligative properties: boiling point elevation and freezing point depression. Chemistry Education Research and Practice, 10(4), 273-280.

[31]. Milenković, D. D., Hrin, T. N., Segedinac, M. D., \& Horvat, S. (2016). Development of a three-tier test as a valid diagnostic tool for identification of misconceptions related to carbohydrates. Journal of Chemical Education, 93(9), 1514-1520. doi: 10.1021/acs.jchemed.6b00261

[32]. Santos, V. C., \& Arroio, A. (2016). The representational levels: Influences and contributions to research in chemical education. Journal of Turkish Science Education, 13(1), 3-18. 